\title{
Agricultural Performance for Human Development: A Case Study of Barak Valley in Assam
}

\author{
Shamintra Ghosh* \\ PhD Research Scholar, Dept-Economics, Assam University, India
}

\begin{abstract}
The objective of the paper is to study linkage among agricultural performance and human development and evaluate sustainability indicators in the Barak Valley zone of Assam. The methodology used in this study was by collection of primary data and field observations. Samples for statistics were taken from heads of rural households in selected Agricultural Development Circles of three districts of Barak Valley. The sample consisted of 450 Households. The present paper analyses the agro-human development linkage of Barak Valley. Each component of agricultural performance is analyzed with the help of factor indices. The factor indices assist to understand the actual scenario of agricultural situation of sample ADOs in Barak Valley. A number of indices have been constructed to address the objectives of the study which includes: (a) Agricultural Performance Index (API), (b) Human development by Quality of Life Index (c)Education Index, (d) Health Index etc. All these indices have been constructed at the household level. Moreover, suitable statistical, regression techniques and econometric models will be used to analyze the relationship among concerned variables of the study.
\end{abstract}

Keywords: Agricultural Performance Index, Quality of Life Index \& Sustainable Rural Development.

\section{Introduction}

Barak Valley consists of three districts of Cachar, Karimganj and Hialakandi in southern part of Assam on the bank of river Barak and her tributaries. The population of the valley is 3,612,581 as per 2011 census. The economy of the Barak Valley is pre dominated by agriculture and allied sectors. More than 58 percent of the total working population in the valley is either cultivators or agricultural laborers and 70.7 percent of its workers earn their livelihood from the primary sector activities. But agriculture is already overcrowded and it shows that only 30.9 percent of the total geographical area in the valley constitutes its net sown area against 41.6 percent in the State of Assam. This means that the Barak Valley suffers from relative scarcity of cultivable land. In the consequence, Barak Valley is constrained to feed as any as 8277 persons per 1000 hectares of cultivable land. The corresponding figures for the Brahmaputra Valley and the State of Assam are 6445 hectares and 6567 hectares respectively whereas the all-India figure is 4305 hectares. Added to the scarcity of cultivable land in the valley, inadequate progress in intensive farming also exists. As such it would be interesting to study the interrelationships between performance of agriculture and human development scenario in the valley.

Previous work

World Development Report (2008), Rosegrant et al (2007), Dutta and Ravallion (1996), Dayal (1984), Dasgupta (1998), Thirtle et al (2001) etc have nicely analyzed the relation between agriculture and incidence of poverty in LDCs. Other studies by Pathasarathy (1975), Singh (2010), Gibson et al (1998), Kennedy (1987), (1990), Bezbruah (1994), Sen (1989), Singh et al (1984) etc made empirical analysis of quality of life in relation with agricultural productivity and rural development.

The main objectives of the study are:-

$>\quad$ To study the relation between agricultural performance and human development.

$>\quad$ To study the relation among agricultural sector, education, health etc.

$>\quad$ To find out the socio-economic factors determining sustainability of agriculture and rural development.

\section{Methodology of the Study}

Data has been collected from both primary and secondary sources. Multistage sampling has been followed. In the Barak Valley region there are six agricultural subdivisions-(1) Cachar district (3 subdivisions), (2) Karimganj district (2 subdivisions) (3) Hailakandi (1 subdivisions). From each subdivision one ADO circle has been selected subject to the condition that the selected circle will represent the entire subdivision. From each ADO circle two villages (one agriculturally developed having at least some marketing network and other agriculturally underdeveloped) has been selected in consultation with Agricultural Development Officer. From the selected villages 450 sample of farming households has been selected for the study. 
A number of indices have been constructed to address the objectives of the study which includes: (a) Agricultural Performance Index (API), (b) Human development by Quality of Life (c) Wealth Index, (d) Health Index, and (e) Education Index. All these indices have been constructed at the household level. Moreover, suitable statistical and regression techniques will be used to analyze the relationship among concerned variables of the study.

The definition and process of calculation of indices are

Agricultural Performance Index

Agricultural performance is defined as results/achievements in the field of agriculture including all aspects- land fertility, marketing, technology and labor productivity. The study has endeavored to make a composite index including all these factors.

Fig-1

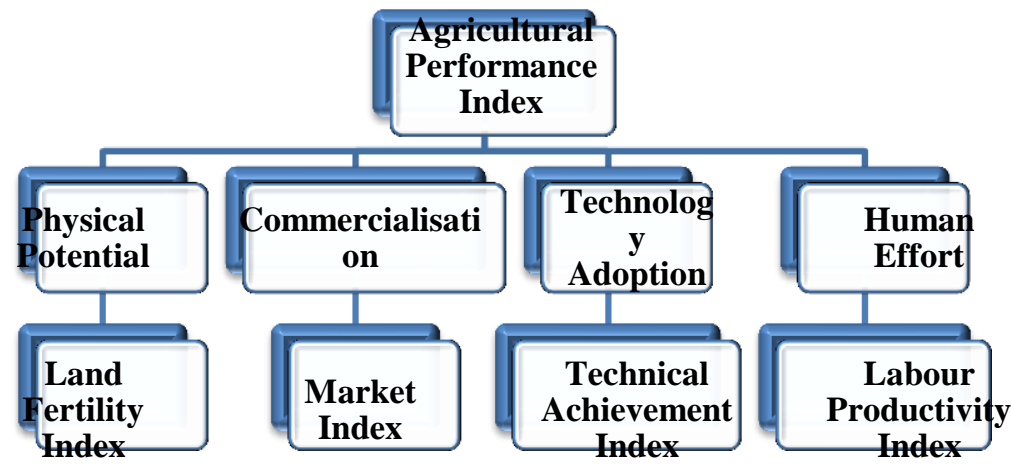

Agricultural Performance Index (API) would comprise the weighted measure of:

1. Physical potential - as measured by levels of land fertility.

2. Availability and accessibility of markets, as measured by commercial sale levels of key agricultural commodities.

3. Level of technological achievements (innovations) as measured by use of improved seeds and other modernizing agricultural technologies.

4. Level of human effort (output per worker).

Factor Indices or dimension indices will be prepared

$$
\mathrm{FI}=\frac{\text { Actual value of the factor-Minimum value of the factor }}{\text { Maximum vaule-Minimum value }}
$$

Agricultural Performance Index $=1 / 4($ Land fertility index $)+1 / 4($ Market index $)+1 / 4($ Technical achievement index $)+1 / 4$ (Workers productivity index)

Wealth Index

Wealth index does not mean property and income of the farmers, rather wealth index is a composite measure of 28 all such indicators which include every facets of human life and his/her different choices. They are 1) House type 2)Separate room for cooking/Kitchen 3) Ownership of house 4) Flooring 5) Toilet facility 6) Source of Electricity/Lighting 7) Main fuel for cooking 8) Source of Drinking Water 5) Car or Tractor 9) Moped or Scooter 10) Telephone 11) Refrigerator 12) Colour TV 13) Black and white TV 14) Bicycle 15) Electric fan 16) Radio 17) Sewing machine 18) Mattress 20) Pressure cooker 21) Chair 22) Cot or bed 23) Table 24) Clock or watch 25) Ownership of livestock 26) Water pump 27) Bullock cart 28) Harvester/Thresher. These indicators have been given weights and scores. On the basis of individual scores of 450 samples, dimension index or wealth index will be made.

The Wealth Index $=$ Actual score of the sample-Minimum score of the sample

Education index

Education index is calculated by taking equal weights of the two indicators- literacy level and child enrolment (if any school-aged child is out of school).

The Literacy Index $=\frac{\text { Actual value of the factor-Minimum value of the factor }}{}$

Therefore the Education Index $=50 \% \times$ Literacy Index $+50 \% \times$ Child Enrolment

Health Index

Health is an important parameter of Human Development. Health Index is prepared with the help of two sub dimensions- Body Mass Index and Child Mortality, giving them equal weights.

Now Factor Index for BMI $=\frac{\text { Actual value of the factor-Minimum value of the factor }}{\text { Maximum vaule-Minimum value }}$

Therefore Health Index $=50 \% \times$ BMI $+50 \% \times$ Child Mortality

Quality of Life Index 
Quality of Life is calculated simply as Human Development Index by three equally weighted dimension indiceswealth index, education index and health index-

Quality of Life Index $=1 / 3$ (wealth index) $+1 / 3$ (education index) $+1 / 3$ (health index)

\section{Data Analysis, Findings and Discussion}

\subsection{Agricultural Performance Index in Barak Valley}

Agricultural performance is a measure of the changes (positive or negative) in the principal variables that constitute the agricultural sector.The study has considered all aspects related to farm practices to include in performance so that an agricultural index can be able to present the entire scenario of agriculture and rural development. Agricultural Performance Index is a composite index of all four dimension index-Land Fertility Index, Market Index, Technology Achievement Index and Labor Productivity Index having equal weights.

Table- 1

Distribution of farmers according to score in API

\begin{tabular}{|c|c|c|c|c|}
\hline Indicator & Agricultural Performance index & Indicator & $\begin{array}{l}\text { Number of } \\
\text { farmers }\end{array}$ & $\begin{array}{ll}\% & \text { of } \\
\text { farmers }\end{array}$ \\
\hline Mean observation & 0.468 & Excellent ( $0.8 \&$ above) & 2 & $1 \%$ \\
\hline Max. observation & 0.854 & Very good $(0.6-0.8)$ & 101 & $22 \%$ \\
\hline \multirow[t]{5}{*}{ Min. observation } & 0.071 & Good $(0.5-0.6)$ & 102 & $23 \%$ \\
\hline & & Average $(0.4-0.5)$ & 87 & $19 \%$ \\
\hline & & Poor/ Less than average $(0.2-0.4)$ & 132 & $29 \%$ \\
\hline & & Very poor/ bad performance $(<0.2)$ & 26 & $6 \%$ \\
\hline & & Total & 450 & 100 \\
\hline
\end{tabular}

Source: Calculated by scholar from 450 samples.

Fig-2

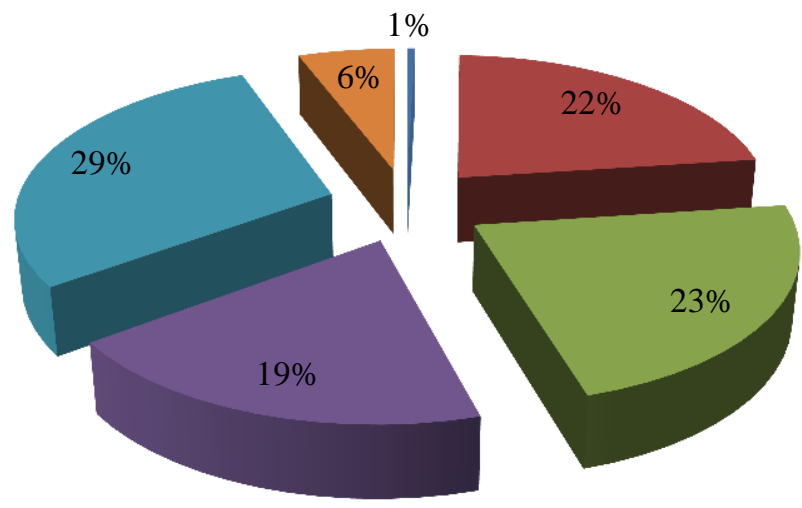

Excellent ( $0.8 \&$ above $)$

- Very good (0.6-0.8)

Good $(0.5-0.6)$

- Average (0.4-0.5)

- Poor/ Less than average ( 0.2-0.4)

- Very poor/ bad performance $(<0.2)$

Distribution of farmers according to score in API

Findings in API

1. The mean value of Agricultural Performance Index is 0.468 in Barak Valley which shows moderate achievement regarding entire agrarian system. The maximum or the best performer scored 0.854 who is sample-56 belonging to Dullabcherra ADO circle. The minimum one is the 0.071 or sample-302 in Motinagar ADO and 0.072 i.e. sample-83 in Sadarashi ADO. Those who have scored more than 0.800 index value belongs to the excellent group and they are only 6 in the study area i.e. only $1 \%$ of the total households. Agricultural performance is indicative of all aspects of agricultural development land fertility or labor efficacy or technology or marketing. Thus the API in Barak Valley shows the medium or moderate performance.

2. 101 farmers or $22 \%$ farmers in Barak Valley denote that they belong to good performer's club. Most of them have performed well in technology achievement or marketing of the crop. Their performance lies in between 0.600 to 0.800 index value.

3. $23 \%$ farmers or a total of 102 samples performed 0.500 to 0.600 group known as good. Moreover the average performers with index value in between 0.400 to 0.500 are $19 \%$ of the farmers or a total of 87 in number. They form a sizable section of farmers in Barak Valley who produce and market the largest amount of crop in Barak Valley. Those producers with high index value of 0.700 or 0.750 or more than 0.800 are very few in number. On the other hand those who performed at lower index value can not 
contribute much to the total crop or marketable surplus. Thus farmers with average or medium index value are more in number and contribute the most to the agricultural output of the Valley.

4. However the farmers with index value of 0.200 to 0.400 are not less in number. They form $29 \%$ of the farming community of the Valley and a total of 132 in my study area. They are regarded as poor performers or unable to utilize the resource properly. Their farm land is overcrowded and output per worker is low. Not only labor productivity the performance in technology adoption or marketing of crops has been low. The lower index indicates that there is misuse and non utilization of resource properly, moreover the steps to remove their inability are also very poor.

5. $6 \%$ performers are there whose index result is below 0.200 which is low enough to be included in the efficiency analysis. They performed badly and are mostly marginal farmers who struggle everyday to earn two square meals for their family.

\subsection{Quality of Life Index in Barak Valley}

Performance in human development has been measured by achievement in quality of life/standard of living. A composite index has been formed to measure the progress in quality of life by 28 indicators of household- housing characteristics, quality of sanitation, electricity, drinking water, cooking fuel, a bunch of electronic goods, essential goods, vehicles etc. Moreover education index made of literacy level and enrolment, health index made of BMI-Body Mass Index and child mortality have been prepared. Quality of life index is a composite measure of all three dimension indices having equal weights.

Table-2

Distribution of farmers according to score in Quality of Life Index

\begin{tabular}{|l|l|l|l|l|}
\hline Indicator & Quality of Life Index & Indicator & $\begin{array}{l}\text { Number of } \\
\text { farmers }\end{array}$ & $\begin{array}{l}\% \\
\text { farmers }\end{array}$ \\
\hline Mean observation & 0.591 & Excellent (0.8 \& above) & 8 & $2 \%$ \\
\hline Max. observation & 0.843 & Very good (0.7-0.8) & 77 & $17 \%$ \\
\hline Min. observation & 0.132 & Good (0.6-0.7) & 163 & $36 \%$ \\
\hline \multirow{5}{*}{} & Moderate/Average $(0.5-0.6)$ & 100 & $22 \%$ \\
\cline { 3 - 5 } & Poor/ Less than average $(0.3-0.5)$ & 94 & $21 \%$ \\
\cline { 3 - 5 } & Very poor/ Negligible $(<0.3)$ & 8 & $2 \%$ \\
\cline { 3 - 5 } & Total & 450 & 100 \\
\hline
\end{tabular}

Source: Calculated by scholar from 450 samples.

Fig-3

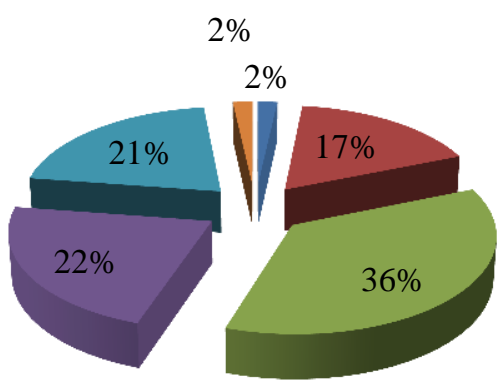

Excellent ( 0.8 \& above)

- Very good (0.7-0.8)

Good (0.6-0.7)

Moderate/Average

$(0.5-0.6)$

Poor/ Less than average (0.3-0.5)

Very poor/

Negligible $(<0.3)$

Distribution of farmers according to score in Quality of Life Index

Findings in QLI

1. India Human Development-2011 Report says, 'The raison d'être of development is to improve the quality of people's lives by creating an environment for them to engage in a wider range of activities, to be healthy and well nourished, to be knowledgeable, and to be able to participate in community life'. Sen (1985) calls them 'basic functioning'. Quality of life of the farmers on the basis of wealth, education and health endeavors to fulfill these preconditions.

2. The quality of life in Barak Valley or human development is 0.591 which is moderate. The highest one is the sample-435 with 0.843 of index value, the $2^{\text {nd }}$ highest is the s-24 with 0.835 and the lowest one is the sample-60 with index 0.132 . The quality of life for the best group of farmers belongs to the index value above 0.800 but only 8 have qualified in this group which makes only $2 \%$ of the total. 
3. Those who have scored in between 0.700 to 0.800 makes the $2^{\text {nd }}$ group and a sizable number of farmers belongs to it. It constitutes $17 \%$ of the total or 77 in number while they definitely performed better in case of wealth index or BMI or mortality. In this group not only mortality is absent but also illiteracy has not been found. They have performed better in taking care of their children to go to the schools. Their higher quality of life has been promoted from all dimension indices.

4. The $3^{\text {rd }}$ group of farmers has scored in between 0.600 to 0.700 ; they are the good performers who constitute the most important club in the quality of life performance. They form $36 \%$ of the total sample farmers or 136 in number, thus making the biggest part of the pie diagram. Most of the farmers in this group performed good in at least two dimensions and deprived in the other. To put it other way there are total 4 sub indices of education and health. On the other hand wealth index is made of 28 indicators but dimension indices have been equally weighted to avoid the possibility of wrong assessment.

5. The fourth group constitutes also large in Barak Valley as $22 \%$ or 100 farmers belong to this club, they are very much average performers while they performed better in half of the indicators.

6. The fifth group of farmers also forms a sizable part of the farming community but they are regarded as poor performers in quality of life index. They scored in between 0.300 to 0.500 . This group makes $21 \%$ of the total or 94 in number in the study area. Their performance is below average and they are struggling in maintaining good score in at least two of the dimension indices.

7. The last group is the one maintaining a life that can be called less than a human life. It is $2 \%$ of the total or 8 out of 450 farmers in Barak Vallley.

\subsection{Linkage between Agricultural Performance Index and Human Development/ Quality of Life}

Table- 3

A Multiple Linear Regression Analysis

\begin{tabular}{l|l|l|l|l|}
\hline Model & $\mathrm{R}$ & $\mathrm{R}$ Square & Adjusted R Square & Std. Error of the Estimate \\
\hline 1 & .711 & .505 & .500 & .094248 \\
\hline
\end{tabular}

We have used our data sets for multiple linear regressions. In this data set, required LFI- Land Fertility Index, MI-Market Index, TAI-Technology Achievement Index and LPI- Labor Productivity Index, are used to predict human development or quality of life index-QLI which is a composite measure of wealth, education and health. From left to right, we use the variables $y, x 1, x 2, x 3$ and $x 4$. In the Model Summary, we see that the coefficient of multiple correlation $r(\mathrm{R})$ is .711, indicating a strong positive linear relationship between the predictors and the dependent variable. The coefficient of determination $r 2$ (R Square) of .505 indicates that, for the sample, $50 \%$ of the variation of QLI can be explained by the variation in LPI, LFI, TAI, MI. But this may be an overestimate for the population from which the sample is drawn, so we use the Adjusted R Square .500 as a better estimate for the population. Finally, the Standard Error of the Estimate is .094248.

Table- 4

Coefficients

\begin{tabular}{|c|c|c|c|c|c|c|}
\hline \multirow{2}{*}{\multicolumn{2}{|c|}{ Model }} & \multicolumn{2}{|c|}{ Un standardized Coefficients } & \multirow{2}{*}{$\begin{array}{l}\text { Standardized } \\
\text { Coefficients } \\
\text { Beta }\end{array}$} & \multirow[b]{2}{*}{$\mathrm{t}$} & \multirow[b]{2}{*}{ Sig. } \\
\hline & & B & Std. Error & & & \\
\hline \multirow[t]{5}{*}{1} & (Constant) & .326 & .019 & & 17.559 & .000 \\
\hline & LFI & .169 & .032 & .192 & 5.321 & .000 \\
\hline & MI & .188 & .022 & .431 & 8.720 & .000 \\
\hline & TAI & .125 & .023 & .224 & 5.326 & .000 \\
\hline & LPI & .041 & .045 & .039 & .924 & .356 \\
\hline
\end{tabular}

a. Dependent Variable: QLI

F-dist- 440.780

Let $y=$ Quality of Life Index-QLI, $x 1=$ Land Fertility Index-LFI, $x 2=$ Market Index-MI, and $x 3=$ Technology Achievement Index-TAI and $x 4=$ Labor Productivity Index-LPI. We use the regression (least squares) equation $\hat{\mathrm{y}}=\mathrm{a}+\mathrm{b} 1 \mathrm{x} 1+\mathrm{b} 2 \times 2+\mathrm{b} 3 \times 3+\mathrm{b} 4 \mathrm{x} 4$ to approximate the population regression equation $\mu \mathrm{y} \mid(\mathrm{x} 1, \quad \mathrm{x} 2, \mathrm{x} 3$, $\mathrm{x} 4)=\alpha+\beta 1 \times 1+\beta 2 \times 2+\beta 3 \times 3$. 
From the Coefficients table above, $\mathrm{a}=.326, \mathrm{~b} 1=.169, \mathrm{~b} 2=.188, \mathrm{~b} 3=.125, \mathrm{~b} 4=.041$ from the first column of numbers (rows and columns transposed from the output), so the sample regression equation is $\hat{y}=.326+.169 \times 1+.188 \times 2+.125 \times 3+.041 \times 4$. From the last two columns of numbers in the table, one gets that $95 \%$ confidence intervals.

The $t$ test is used for testing the various null hypotheses $\beta \mathrm{i}=0$. It can be used similarly to test the null hypothesis $\alpha=0$, but this is of much less interest. In this case, we read from the above table that, as an example, for $\mathrm{H} 0: \beta 1=0, \mathrm{Ha}: \beta 1 \neq 0$. Since the $p$-value $(\mathrm{Sig} .=.000)$ for that $t$ test is less than .001 , we can reject the null hypothesis of $\beta 1=0$. Notice that at the $\alpha=.05$ level, we would accept the null hypothesis $\beta 2=0$ since $p=.05$. Also, notice that 0 is in the $95 \%$ confidence interval for $\beta 2$ (barely). But if using these $t$ tests, keep in mind the dangers of using multiple hypothesis tests and/or finding multiple confidence intervals on the same set of data.

The relationship between two variables is explained with the help of $\mathrm{R}$ square 0.505 i.e. $50 \%$ of the variation in human development is explained by variation in agricultural performance in Barak Valley. The value of $\mathrm{F}$ 440.780 is the quotient of Mean Square Regression and the Mean Square Residual -MSR and MSE respectively. The following diagram shows the positive linear relation between agricultural performance index and quality of life index.

Curve Estimation

QLI

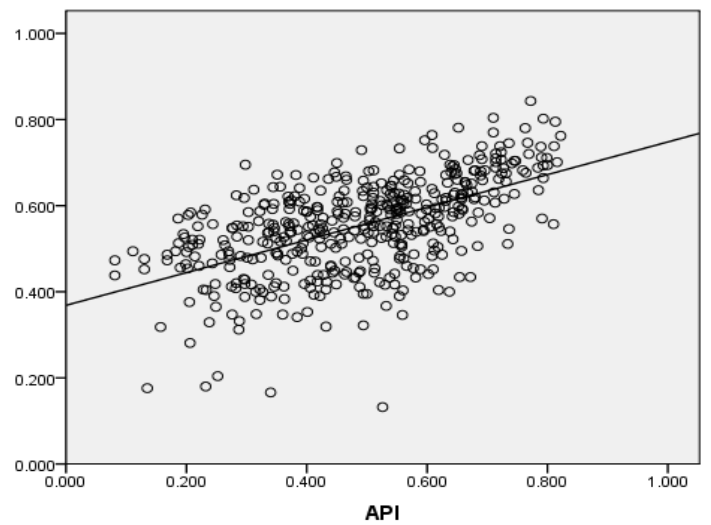

\subsection{Determinants of Human Development in Barak Valley}

Table- 5

Human Development \& its Factors [Results of Regression Analysis]

\begin{tabular}{|c|c|c|c|c|c|c|c|c|}
\hline $\begin{array}{l}\text { Regression } \\
\text { Model } \\
\text { Direct } \\
\text { Linkage }\end{array}$ & $\mathrm{R}$ & R Square & $\begin{array}{l}\text { Adjusted R } \\
\text { Square }\end{array}$ & $\begin{array}{l}\text { Std. Error of } \\
\text { the Estimate }\end{array}$ & F-Dist. & Sig. & Constant & $\mathrm{B}$ \\
\hline QLI \& WI & .713 & .509 & .508 & .093577 & 463.816 & .000 & .241 & .626 \\
\hline QLI \& EI & .875 & .765 & .765 & .064663 & 146.23 & .000 & .317 & .445 \\
\hline QLI \& HI & .501 & .251 & .249 & .094892 & 149.909 & .000 & .306 & .402 \\
\hline QLI \& LFI & .417 & .174 & .172 & .121317 & 95.511 & .000 & .403 & .367 \\
\hline QLI \& MI & .662 & .438 & .437 & .100079 & 349.118 & .000 & .440 & .289 \\
\hline QLI \& TAI & .546 & .298 & .296 & .111889 & 189.788 & .000 & .427 & .304 \\
\hline QLI \& LPI & .436 & .190 & .189 & .120120 & 105.307 & .000 & .458 & .460 \\
\hline QLI \& MPI & -.706 & .498 & .497 & .138876 & 444.384 & .000 & .864 & -1.036 \\
\hline \multicolumn{9}{|c|}{ Indirect Linkage } \\
\hline WI \& LPI & .596 & .355 & .354 & .10169 & 246.982 & .000 & .013 & .497 \\
\hline WI \& TAI & .736 & .541 & .540 & .16209 & 528.713 & .000 & .106 & 1.158 \\
\hline WI \& MI & .727 & .529 & .528 & .21005 & 502.601 & .000 & .294 & 1.163 \\
\hline HI \& LPI & .850 & .700 & .695 & .12620 & 327.20 & .071 & .052 & .135 \\
\hline $\begin{array}{l}\text { Schooling } \\
\text { \& LPI }\end{array}$ & .575 & .330 & .329 & .10367 & 220.766 & .000 & .122 & .023 \\
\hline $\begin{array}{l}\text { Schooling } \\
\text { \& TAI }\end{array}$ & .669 & .448 & .446 & .17789 & 363.38 & .000 & .170 & .050 \\
\hline $\begin{array}{l}\text { Schooling } \\
\text { \& MI }\end{array}$ & .802 & .642 & .642 & .182956 & 804.934 & .000 & .044 & .076 \\
\hline
\end{tabular}


Human Development is shown with Quality of Life which is a weighted index of wealth, education and health. The QLI is found to depend positively on all direct and indirect factors except poverty. The agricultural, economic and social variables are found to have influenced the human development largely in Barak Valley for sample farms. A summary table has been prepared consisting the results of Quality of Life with all of its predictors.

\subsubsection{Summary Interpretation of Direct Linkage Factors \& Dependent variable- QLI}

1. QLI \& WI- The coefficient of multiple correlations $(\mathrm{R})$ is .713, indicating a good positive linear relationship. The coefficient of determination $\mathrm{r} 2$ (R Square) of .509 indicates that for the sample, $50 \%$ of the variation in Quality of Life can be explained by the variation in Wealth Index. But this may be an overestimate for the population from which the sample is drawn, so we use the Adjusted R Square as a better estimate for the population i.e .508. Finally the Std. Error of the Estimate is .093577 . The value of F dist. 463.816 is the quotient of Mean Square Regression and the Mean Square Residual -MSR and MSE respectively and highly significant.

2. QLI \& EI-We find that the coefficient of multiple correlations $(\mathrm{R})$ is .875, indicating a strong positive linear relationship. The coefficient of determination $\mathrm{r} 2$ (R Square) of .765 indicates that for the sample, $76 \%$ of the variation in Quality of Life can be explained by the variation in Market Index. The Adjusted R Square for the population is .765. Finally the Std. Error of the Estimate is 0.064663 . The value of F dist. 146.23 is highly significant.

3. QLI \& HI-The coefficient of multiple correlations $(\mathrm{R})$ is .501, indicating a strong positive linear relationship. The coefficient of determination $\mathrm{r} 2$ (R Square) of .251 indicates that for the sample, $25 \%$ of the variation in Quality of Life can be explained by the variation in Health Index. The Adjusted R Square for the population is .249. Finally the Std. Error of the Estimate is 0.094892. The F dist. is 149.909 and highly significant.

4. QLI \& LFI-The coefficient of multiple correlations(R) is .417 , indicating a moderate, positive linear relationship. The coefficient of determination $\mathrm{r} 2$ (R Square) of .174 indicates that for the sample, $17 \%$ of the variation in Quality of Life can be explained by the variation in Land Fertility Index. The Adjusted R Square is .172. Finally the Std. Error of the Estimate is 0.121317. The F dist. is 95.511 and highly significant.

5. QLI \& MI-The coefficient of multiple correlations $(\mathrm{R})$ is .662, indicating a good positive linear relationship. The coefficient of determination $\mathrm{r} 2$ (R Square) of .438 indicates that for the sample, $43 \%$ of the variation in Quality of Life can be explained by the variation in Market Index. The Adjusted R Square is .437. Finally the Std. Error of the Estimate is 0.100079 . The F dist. is 349.118 and highly significant.

6. QLI \& TAI-The coefficient of multiple correlations(R) is .546, indicating a good positive linear relationship. The coefficient of determination $\mathrm{r} 2$ (R Square) of .298 indicates that for the sample, $29 \%$ of the variation in Quality of Life can be explained by the variation in Technology Achievement Index. The Adjusted R Square is .296. Finally the Std. Error of the Estimate is 0.111889 . The F dist. is 189.788 and highly significant.

7. QLI \& LPI-The coefficient of multiple correlations $(\mathrm{R})$ is .436, indicating a moderate positive linear relationship. The coefficient of determination $\mathrm{r} 2$ (R Square) of .190 indicates that for the sample, $19 \%$ of the variation in Quality of Life can be explained by the variation in Labour Productivity. The Adjusted R Square is .189. Finally the Std. Error of the Estimate is .120120. The F dist. is 105.307 and highly significant.

8. QLI \& MPI-The coefficient of multiple correlations(R) is .706, indicating a strong negative linear relationship. The coefficient of determination $\mathrm{r} 2$ (R Square) of .498 indicates that for the sample, $49 \%$ of the variation in Quality of Life can be explained by the variation in Multidimensional Poverty Index. The Adjusted R Square is .497. Finally the Std. Error of the Estimate is .138876. The F dist. is 444.384 and highly significant.

3.4.2 Summary Interpretation of Indirect Linkage Factors

1. WI \& LPI- The coefficient of multiple correlations(R) is .596, indicating a good positive linear relationship. The coefficient of determination $\mathrm{r} 2$ (R Square) of .355 indicates that for the sample, 35\% of the variation in Wealth Index can be explained by the variation in Labour Productivity Index. The Adjusted R Square is a better estimate for the population i.e .354. The Std. Error of the Estimate is .10169. The value of F dist. 246.982 is the quotient of Mean Square Regression and the Mean Square Residual -MSR and MSE respectively and highly significant.

2. WI \& TAI-We find that the coefficient of multiple correlations $(\mathrm{R})$ is .736 , indicating a strong positive linear relationship. The coefficient of determination $\mathrm{r} 2$ (R Square) of .541 indicates that for the sample, $54 \%$ of the variation in Wealth Index can be explained by the variation in Technology Achievement Index. The 
Adjusted R Square for the population is .540. Finally the Std. Error of the Estimate is 0.16209 . The value of F dist. 528.713 is highly sinficant.

3. WI \& MI-The coefficient of multiple correlations(R) is .727, indicating a strong positive linear relationship. The coefficient of determination $\mathrm{r} 2$ (R Square) of .529 indicates that for the sample, 52\% of the variation in Wealth can be explained by the variation in Market Index. The Adjusted R Square is .528. Finally the Std. Error of the Estimate is .21005. The F dist. is 502.601 and highly significant.

4. HI \& LPI- The coefficient of multiple correlations $(\mathrm{R})$ is .850 , indicating a strong positive linear relationship. The coefficient of determination $\mathrm{r} 2$ (R Square) of .700 indicates that for the sample, $70 \%$ of the variation in Health Index can be explained by the variation in Labour Productivity. The Adjusted $R$ Square is a better estimate for the population i.e .695. Finally the Std. Error of the Estimate is 0.12620 . The value of F dist. 327.20 is highly significant.

5. Schooling \& LPI-We find that the coefficient of multiple correlations $(\mathrm{R})$ is .575 , indicating a good positive linear relationship. The coefficient of determination $\mathrm{r} 2$ (R Square) of .330 indicates that for the sample, $33 \%$ of the variation in Schooling can be explained by the variation in Labour Productivity. The Adjusted R Square for the population is .329. Finally the Std. Error of the Estimate is 0.10367 . The value of F dist. 220.766 is highly sinficant.

6. Schooling \& TAI-The coefficient of multiple correlations $(\mathrm{R})$ is .669 , indicating a good positive linear relationship. The coefficient of determination $\mathrm{r} 2$ (R Square) of .448 indicates that for the sample, $44 \%$ of the variation in schooling can be explained by the variation Technology Achievement Index. The Adjusted R Square is .446. Finally the Std. Error of the Estimate is 0.17789. The F dist. is 363.63 and highly significant.

7. Schooling \& MI-The coefficient of multiple correlations(R) is .802 , indicating a strong positive linear relationship. The coefficient of determination $\mathrm{r} 2$ (R Square) of .642 indicates that for the sample, $64 \%$ of the variation in schooling can be explained by the variation in Market. The Adjusted R Square is 642 . Finally the Std. Error of the Estimate is 0.182956 . The F dist. is 804.934 and highly significant.

\section{Conclusion}

Thus we find that there exists a vital relation between factors of human development and agricultural development. Human development expands the productivity of the farmers in the form of raising the skill of farming, giving access to modern technology, more market information, extension services etc. Both issues are interlinked heavily to raise the growth rate, reduce the poverty and improve the human development situation. Economic development in true sense of the term requires the reinforcing effect of both agrarian and human development policies.

\section{References}

[1]. Gibson, C \& Fincham, R.(1993): Nutritional survey of Ezingolweni and Nkandla. published report. Durban: University of Natal.

[2]. Goswami, P.C. (1994): The Economic Development of Assam, Kalyani Publishers, Ludhiana.

[3]. Government of Assam (2009): Statistical Handbook, Directorate of Economics and Statistics, Guwahati.

[4]. Dasgupta, Partha (1998). The economics of poverty in poor countries. Scandinavian Journal of Economics, 100:1, 41-68.

[5]. Sen, A K (1981): Poverty and Famines: An Essay on Entitlement and Deprivation, Clarendon Press, Oxford.

[6]. Srinivasan, T N (2000): 'Growth and Poverty Alleviation: Lessons from Development Experience', Paper presented at the Symposium on Alternative Development Paradigms and Poverty Reduction, Asian Development Bank Institute, Tokyo.

[7]. Datt, G and M Ravallion (1996a): 'Why have some Indian States Done Better than Others at Reducing Rural Poverty?' Economica, 65:257, pp 17-38. - (1998): 'Farm Productivity and Rural Poverty in India', Journal of Development Studies, April. -(1999): 'When is Growth Pro-Poor? Evidence from the Diverse Experiences of India's States', Policy Research Working Paper, World Bank, Washington, DC. (2001): 'Why has Economic Growth Been More Pro-poor in Some States of India than Others?' Journal of Development Economics.

[8]. Dreze J and Sen A.K. (2002): India: Development and Participation, Oxford University Press, New Delhi.

[9]. Gallup, John, Radelet, Steven and Warner, Andrew (1997). Economic Growth and Income of the Poor. Harvard Institute for International Development, CAER II Discussion Paper No 36. 